(A us dem thierphysiologischen Laboratorium der landwirthschaftlichen Hochschule zu Berlin.)

\title{
Zur Kritik von Hammerschlag's Methode der Dichtebestimmung von Blut und Serum.
}

\author{
Von
}

cand. med. Leo Zuntz, Berlin.

Bei ihren Untersuchungen im Hochgebirge hatten $\mathrm{S} \mathrm{ch} \mathrm{u} \mathrm{mbu} \mathrm{r} \mathrm{g}$ und Zuntz an sich mittels der Hammerschlag'schen Methode so niedrige Werthe fiir ibr Blutserum gefunden, dass ein Febler bei den Bestimmungen angenommen werden musste und deshalb von einer Veröffentlichung derselben Abstand genommen wurde; Um die Ursache anfauklären, sollten weitere Versuche im Laboratorium angestellt werden, deren Ausfïbrung mir übertragen wurde.

Das Serum wurde dabei in einer von den Hammerschlagschen Angaben etwas abweichenden, von Schumburg zuerst angewandten Weise gewonnen. Die zum Anfsaugen des Blutes bestimmten Capillaren wurden nicht erst mit oxalsaurem Kali angefeuchtet, sondern trocken belassen. Es gerinnt dann das Blut in den versiegelten, senkrecht anfbewahrten Capillaren und man kann am folgenden Tage, nach Anfeilen und Abbrechen des Endes des Röhrchens, Blutkörperchen und Fibrin als einen dünnen, zusammenhängenden Faden herausziehen. In dem wieder versiegelten Röhrchen bleibt das Serum als eine ganz leicht röthlich getriibte Flüssigkeit zurïck. Innerhalb einiger Stunden senken sich die wenigen noch suspendirten Blutkörperchen als ein zusammenhängender Ring. Feilt man oberhalb desselben ab, so kann man einen vollständig wasserhellen Tropfen Serum in die Chloroformbenzolmischung einblasen. Die kleine Aenderung bietet den Vortheil, dass jede Vermischnng mit einem fremden Körper wie oxalsaures Kali ausgeschlossen ist und dass man in jedem Fall das reine Serum ohne Fibrin erhält. 
In einer Anzahl mit von S. und $Z$. in dieser Weise gewonnenem Serum angestellten Versuchen erhielt ich nun, wie erstere im Gebirge ganz auffallend niedrige, zwischen 1,013 und 1,017 sich bewegende Werthe. Alle diese Bestimmungen bemiuhte ich mich, möglichst exakt zu machen, d. h. ich betrachtete den Versuch erst als abgeschlossen, wenn der Tropfen etwa 1 Minute nicht mehr gestiegen oder gesunken war. Ehe dies erreicht war, verging gewöhnlich ungefähr eine Viertelstunde.

Es lag nahe, die nngewöhnlich niedrigen Werthe auf Diffusionsvorgänge zwischen der Schwimmflitssigkeit und dem Serumtropfen, speciell auf eine Benzolaufnahme seitens der letzteren, während der verhältnissmässig langen Versuchsdauer zurückzuführen. Für etwas derartiges sprechen auch die sichtbaren Veränderungen an den Tropfen. Der wasserhell und völlig durchsichtig in die Flüssigkeit gebrachte Tropfen wird nach etwa 1. Minute opaleszirend, trübt sich immer mehr und wird sehliesslich ganz milchig und undurchsichtig.

Um dies Verhalten näher zu beobachten, stellte ich eine Reihe Versuche in der Weise an, dass ich das spezifische Gewicht der Schwimmflüssigkeit vorher mit der Mohrschen Waage bestimmte und die Mischung so herstellte, dass ibr Gewicht etwas niedriger war, als das des zu bestimmenden Serums. Regelmässig sank der hereingebrachte Tropfen zunächst deutlich, um dann doch als Endresultat nach 10--25 Min. ein niedrigeres Gewicht als das der ursprïnglichen Schwimmflïssigkeit zu ergeben, ein sicherer Beweis, dass die Tropfen in der Mischung leichter geworden waren.

Solcher Versuche wurde zunächst eine Anzahl mit von S. und Z. gewonnenem Serum angestellt; die Resultate sind fast durchweg dieselben. Ich gebe bei diesen und allen folgenden Versuchen die specifischen Gewichte auf $15^{0}$ reducirt an, um besser vergleichbare Werthe zu haben. Die Reduktion ist unter der Annahme gemacht, dass Blut und Serum ihre Dichte bei Aenderung der Temperatur wie Wasser ändern.

Ein Beispiel mag genügen. Ich bezeichne dabei mit $m s$ das spezifische Gewicht der Schwimmflüssigkeit zu Beginn des Versuches, mit $s$ das am Ende des Versuches gewonnene, das dem des durch Diffusion leichter gewordenen Serums entspricht. 
Z. Krit. v. Hammerschlag's Meth. d. Dichtebestimm. v. Blut u. Serum. 541

1. Capillare $m s=1,018110 \mathrm{~h} 43^{\circ}$ grosser klarer Tropfen sinkt.

$$
s=1,016511 \mathrm{~h} 3^{\prime} \text {. }
$$

2. Capillare $m s=1,018111 \mathrm{~h} 20^{\prime}$ Tropfen sinkt.

$$
s=1,016011 \mathrm{~h} 40^{\circ} \text {. }
$$

3. Capillare $m s=1,017311 \mathrm{~h} 50^{\circ}$ Tropfen sinkt.

$$
s=1,0164 s=12 \mathrm{~h} 10^{\prime}
$$

Zu dem letzten Versuch ist noch als besonders interessant zu bemerken, dass der Serumtropfen 5 Minuten nach Beginn des Versuches zu schwimmen schien. Ein Theil der Mischung wurde darauf abgegossen, und die Wägung ergab $s=1,0198$. Inzwischen war aber der Tropfen wieder gestiegen und die endgiltige Bestimmung ergab dann den oben angegebenen Werth $s=1,0164$.

Die weiteren Versuche dieser Art wurden mit in grösseren Mengen vom Kaninchen und Hund gewonnenem Serum angestellt. Das wahre spezifische Gewicht desselben konnte mit einem kleinen ca. 2,5 ccm fassenden Pyknometer bestimmt und so die Schwimmfliussigkeit in ihrem Gewicht von vornherein dem des Serums möglichst angenähert werden. Auch hier erhielt ich dieselben Resultate, wie einige Versuchsziffern zeigen mögen.

Das spez. Gewicht des Serums war mittels Pyknometer gefunden $s=1,025$.

$\mathrm{Sch}$ im m versuche.

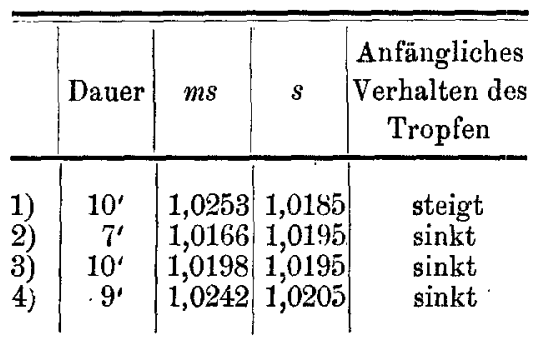

Ganz gleiche Versuche, wenn auch in geringerer Zahl, wurden auch mit defibrinirtem Blut angestelit und ergaben dasselbe Resultat, wie die nachfolgende kleine Tabelle zeigt. Bemerken möchte ich dabei noch, dass Blut sowohl wie Serum, soweit letzteres nicht aus den Capillaren in die Schwimmflüssigkeit eingeblasen wurde, aus einem unten horizontal gebogenen und unter die Oberfläche der Mischung geführten Röhrchen in letztere gebracht wurde, so dass durch die Art der Einfuhrung keine Neigung zum Steigen oder Sinken ertheilt wurde. 
Das spezifische Gewicht des einem Hunde entnommenen Blutes war pyknometrisch festgestellt auf $s=1,0461$.

S chwimm versuche.

\begin{tabular}{l|c|c|c|c}
\hline & Dauer & $m s$ & $s$ & $\begin{array}{c}\text { Anfängliches } \\
\text { Verhalten des } \\
\text { Tropfen }\end{array}$ \\
\hline 1) & $15^{\prime}$ & 1,0463 & 1,0415 & steigt \\
2) & $15^{\prime}$ & 1,0425 & 1,0415 & $\begin{array}{l}\text { sinkt } \\
\text { sinkt }\end{array}$ \\
\hline
\end{tabular}

Um die durch diese Versuche wahrscheinlich gewordenen Diffusionsvorgänge weiter zu verfolgen, brachte ich grössere Miengen Blut oder Serum im Scheidetrichter durch Schütteln in intensive Berührung mit Chloroform mit Benzol oder einem Gemisch beider von bekannter Dichte. Dabei nahm jch, um das Verbältniss beider Flüssigkeiten zu einander bei den gewöhnlichen Schwimmversuchen einigermaassen nachzuahmen, meist nur 1/20-1/40 der Gesammtmenge an Blut oder Serum. So konnte ich von vornherein, selbst unter der Annahme eines Molekülaustausches zwischen beiden Flüssigkeiten, bei diesen Versuchen eine Gewichtsänderung der Scbwimmflüssigkeit in Folge des nngleichen Mengenverhältnisses nicht erwarten. Ich gebe deshalb bei dem Bericht über diese Versuche immer nur die Zahlen für Blut und Serum, wenn auch die anderen stets genommen wurden. Nebenbei sei noch bemerkt, dass es mir auch nie gelang, nach Verdampfen der Schüttelflüssigkeit in derselben Spuren von Eiweiss nachzuweisen.

\section{Sebuttelversuehemit Serum.}

1. $5 \mathrm{ccm}$ Kaninchenserum, vorher pyknometrisch bestimmt zu 1,0231, werden geschüttelt mit $200 \mathrm{ccm}$ Chloroform. Das vorher klare Serum wird milchig getrübt, völlig undurchsichtig. Am nächsten Tage ergiebt die pyknometrische Bestimmung desselben $s=1,1519$.

2. $5 \mathrm{ccm}$ desselben Serums $+200 \mathrm{ccm}$ Benzol. Aehnliche, aber mehr dunkle, braune Trübung. Pyknometrische Bestimmung $s=1,0189$.

3. $10 \mathrm{ccm}$ Hundeserum, dessen Gewicht $=1,0236$ bestimmt ist, werden geschüttelt mit $300 \mathrm{ccm}$ einer Chloroformbenzolmischung vom Gewicht $m s=$ 1,0242. Am nächsten Morgen schwimmt das Serum als eine grauröthliche Masse über der Mischung. Die pyknometrische Bestimmung ergiebt $s=1,0182$. 
Z. Krit. v. Hammerschlag's Meth. d. Dichtebestimm. v. Blut u. Serum. 543

\section{Sehüttelversuehemit Blut.}

4. $5 \mathrm{ccm}$ Hundeblut vom specifischen Gewicht $s=1,0461$ werden geschüttelt mit $10 \mathrm{ccm}$ Chloroform. Es bildet sich ein dicker hellrother Brei, der nicht in seine Bestandtheile zu zerlegen ist.

5. $5 \mathrm{ccm}$ desselben Blutes $+10 \mathrm{ccm}$ Benzol.

Gewicht des Benzols vor dem Versuch $s=0,8755\left(t=18,9^{\circ}\right)$

$$
\begin{aligned}
& " \quad, \quad \text { nach }, \quad " s=0,8763\left(t=18,9^{\circ}\right) \\
& \text { " Blutes " " } " s=1,0026 \text {. }
\end{aligned}
$$

6. $5 \mathrm{ccm}$ desselben Blutes $+200 \mathrm{~cm}$ einer Chloroformbenzolmischung vom spezifischen Gewicht $m s=1,0467$ werden geschüttelt.

Am folgenden Tag schwimmt das in seiner Farbe wenig veränderte Blut oben. Die Gewichtsbestimmung ergiebt $s=1,0401$.

Aus diesen Versuchen geht Folgendes hervor: Blut sowohl wie Serum nehmen bei kräftigem Schütteln mit diesen Stoffen Chloroform und Benzol anf, wie die Versuche 1, 2, 4 und 5 zeigen. Auf das Benzol üben sie aber eine bedeutend stärkere Anziehungskraft, so dass beim Schïtteln mit einer Mischung beider Blut und Serum leichter werden. Da nun das spezifische Gewicht des Chloroforms von demjenigen des Blutes und Serums in bedeutend stärkerem Maasse nach oben abweicht - es beträgt 1,526 - als das Benzol nach unten, so kann ersteres, wenn überhaupt, jedenfalls nur in minimalen Mengen aufgenommen werden. Schliesslich zeigt noch der Versuch 5, in welchem Blut- und Benzolmenge zu einander im Verbältniss $1: 2$ stehen, dass ein Uebergang von Blutbestandtheilen in das Benzol nicht stattfindet, da dessen Gewicht nach dem Versuch so gut wie unverändert ist.

Aus diesen Beobachtungen leiten sich eine Anzahl Cautelen ab, die seitdem im Zuntz'schen Laboratorium beobachtet werden. Da die Diffusionsvorgänge allmählich erfolgen, kommt es vor Allem darauf an, die Bestimmungen in möglichst kurzer Zeit zu Ende zu führen. Bei Serumbestimmungen haben wir an dem Trübwerden der Tropfen, das meist nach 1--2 Minuten eintritt, ein sicheres Zeichen für den Beginn der Diffusion, und beim Blut können wir eine ähnliche Zeit annehmen. Das sicherste Mittel, schnell fertig zu werden, ist nun, die Schwimmflüssigkeit vor Beginn der Probe durch Bestimmungen mit der Mohr'schen Waage dem vermutheten Gewicht der zu bestimmenden Flïssigkeit möglichst anzunähern. Ein einmaliges Zugiessen einiger Tropfen Chloroform oder Benzol wird dann meist zum Ziele führen. Bei Serumbestimmungen em- 
pfiehlt es sich noch, stets 2 oder 3 Capillaren herzustellen, den Tropfen aus der ersten zum Schwimmen zu bringen, dann den aus der zweiten hineinzublasen und etwaige Correkturen nach dem Verhalten dieses oder des noch später hinzugebrachten dritten anzubringen, olne sich dann mehr um den inzwischen veränderten ersten resp. zweiten zu kümmern.

Um andere Untersucher vor unnöthiger Arbeit zu bewahren, möchte ich zum Schluss noch bemerken, dass ich mit einer ganzen Reihe Körper Versuche darüber angestellt habe, ob sie geeignet seien, Chloroform und Benzol za ersetzen. Sie erwiesen sich sämmtlich aus dem einen oder anderen Grunde als unbrauchbar. Es waren dies:

Allylsenföl, Acetessigsaures Acthyl, Benzaldehyd, Benzoesaures Aethyl, Eugenol, Oxalsaures Aethyl, Methylbenzoat, Diäthylacetessigäther, Dimethylanilin, Amylcblorid. 